\title{
Emotional support, negative interaction and DSM IV lifetime disorders among older African Americans: findings from the national survey of American life (NSAL)
}

\author{
Karen D. Lincoln ${ }^{1}$, Robert Joseph Taylor ${ }^{2,3,4}$, Kai McKeever Bullard ${ }^{5}$, Linda M. Chatters ${ }^{2,3,4,6}$, \\ Amanda Toler Woodward ${ }^{7}$, Joseph A. Himle ${ }^{2,8}$ and James S. Jackson ${ }^{3}$ \\ ${ }^{1}$ School of Social Work, University of Southern California, Los Angeles, CA, USA \\ ${ }^{2}$ School of Social Work, University of Michigan, Ann Arbor, MI, USA \\ ${ }^{3}$ Institute for Social Research, University of Michigan, Ann Arbor, MI, USA \\ ${ }^{4}$ Program for Research on Black Americans, University of Michigan, Ann Arbor, MI, USA \\ ${ }^{5}$ Northrop Grumman Corporation, Atlanta, GA, USA \\ ${ }^{6}$ School of Public Health, University of Michigan, Ann Arbor, MI, USA \\ ${ }^{7}$ School of Social Work, Michigan State University, East Lansing, MI, USA \\ ${ }^{8}$ Department of Psychiatry, University of Michigan, Ann Arbor, MI, USA \\ Correspondence to: Dr K. D. Lincoln, E-mail: klincoln@usc.edu
}

\begin{abstract}
Objectives: Both emotional support and negative interaction with family members have been linked to mental health. However, few studies have examined the associations between emotional support and negative interaction and psychiatric disorders in late life. This study investigated the relationship between emotional support and negative interaction on lifetime prevalence of mood and anxiety disorders among older African Americans.
\end{abstract}

Design: The analyses utilized the National Survey of American Life.

Methods: Logistic regression and negative binomial regression analyses were used to examine the effect of emotional support and negative interaction with family members on the prevalence of lifetime DSM-IV mood and anxiety disorders.

Participants: Data from 786 African Americans aged 55 years and older were used.

Measurement: The DSM-IV World Mental Health Composite International Diagnostic Interview (WMH-CIDI) was used to assess mental disorders. Three dependent variables were investigated: the prevalence of lifetime mood disorders, the prevalence of lifetime anxiety.

Results: Multivariate analysis found that emotional support was not associated with any of the three dependent variables. Negative interaction was significantly and positively associated with the odds of having a lifetime mood disorder, a lifetime anxiety disorder and the number of lifetime mood and anxiety disorders.

Conclusions: This is the first study to investigate the relationships among emotional support, negative interaction with family members and psychiatric disorders among older African Americans. Negative interaction was a risk factor for mood and anxiety disorders among older African Americans, whereas emotional support was not significant. Copyright (C) 2010 John Wiley \& Sons, Ltd.

\footnotetext{
Key words: social support; anxiety; mood disorder; depression; elderly blacks; support network; negative interaction History: Received 1 May 2009; Accepted 14 July 2009; Published online 15 February 2010 in Wiley InterScience (www.interscience.wiley.com).

DOI: $10.1002 /$ gps.2383
}

\section{Introduction}

Social support is important for health and well-being across the life course, particularly in late life. Among older adults, social support has been consistently linked to mental health outcomes, including symptoms of depression (Travis et al., 2004) and anxiety (Mehta et al., 2004). Few studies, however, have examined the 
association between social relationships and diagnosable mental disorders in late life, particularly among older African Americans. In addition, in comparison to research on social support, relatively little attention has been given to the potentially harmful effects that may occur as a result of negative interaction with family members.

The present study investigates the relationship between emotional support and negative interaction with family members on lifetime mental disorders among older African Americans. It builds on recent findings that $23 \%$ of older African Americans met criteria for at least one lifetime DSM-IV psychiatric disorder (Ford et al., 2007). This analysis supports recent commentaries calling for greater understanding of potential protective factors (e.g., family support networks) in the development of mental disorders among ethnic minorities (Okereke and Faison, 2008).

A long tradition of research has documented the importance of family support networks for African Americans (Taylor et al., 1990; Chatters et al., 2002). Extended family networks and relationships are important resources for a variety of concerns including assistance when ill or disabled (Dilworth-Anderson et al., 1999), providing a place to live when confronting homelessness (Taylor et al., 2003) and assistance in coping with psychiatric problems (Woodward et al., 2008). For example, a recent study found that social support from family and friends was associated with fewer depressive symptoms among African Americans (Lincoln et al., 2005). However, in addition to the noted benefits of family support, emerging evidence suggests that not all relationships with family members are positive and that negative interactions with family members may be detrimental to mental health.

The concept of negative interactions refers to unpleasant social encounters and interactions that are characterized by conflict, excessive demands and/or criticism (Lincoln, 2000). Several terms are used to describe these interactions including social negativity, social undermining, and problematic social relationships (see review by Lincoln, 2000). Within the gerontological literature, negative interaction is the term most consistently used (Rook, 1984; Krause, 2005; Lincoln, 2007). Negative interactions are regarded as a natural consequence of participation in social networks and can be a fairly common occurrence among family members (Rook and Ituarte, 1999), especially when extensive support is provided (Newsom and Schulz, 1998). Thus, social support and negative interactions frequently co-occur, while at the same time having distinct effects on mental health. Negative interactions with family are among the most upsetting stressors that people experience (e.g., Bolger et al.,
1989; Neighbors, 1997). Even when negative interactions occur infrequently, they adversely impact physical and mental health (Rook, 1984; Krause, 2005).

Furthermore, empirical findings indicate that negative interactions are important predictors of psychological functioning (Rook, 1984; Krause, 2005), negative affect (Newsom et al., 2003), heightened physiological reactivity (King et al., 2002), increased susceptibility to infectious disease (Cohen et al., 1997), declines in physical functioning (Seeman and Chen, 2002), and increased mortality (Tanne et al., 2004). A nationally representative sample of adults aged 21-54 (Zlotnick et al., 2000; Bertera, 2005) found that, across a variety of networks (e.g., spouses, relatives, and friends), negative interaction with social network members was associated with a higher number of anxiety and mood disorder episodes. Finally, a small, but emerging literature among African Americans indicates that negative interaction with family members is associated with increased psychological distress among both elderly (Okun and Keith, 1998) and adults of all ages (Lincoln et al., 2005; Lincoln et al., 2007).

Despite the distinct influence of social support and negative interactions on mental health, there is some evidence that the mechanisms through which these influences occur are similar. Reviews of the literature on social support indicate that emotional support, in particular (e.g., being cared for and loved), is especially beneficial for health and well-being, possibly due to a protective role in bolstering positive self-regard (e.g., self-esteem and self-efficacy). Similarly, the impact of negative interactions with family members is thought to work by instilling negative self-attributions which lead to negative mental states (e.g., psychological distress, depression, and anxiety). Prior studies indicate that emotional support and negative interaction have a weak, negative correlation (Lincoln, 2000). This is primarily due to the fact that emotional support and negative interaction, while occurring simultaneously within social networks, are conceptually different dimensions with distinct effects on mental health (Lincoln et al., 2003b).

This study examines the association between emotional support and negative interaction on the lifetime prevalence of mood and anxiety disorders among older African Americans using data from the National Survey of American Life (NSAL). It contributes to the existing knowledge in several ways. This is the first study that examines the influence of emotional support and negative interactions on mental disorders among older African Americans. It builds upon the limited amount of available literature on the influence of negative interaction on a variety of outcomes 
including psychological distress. Further, it is one of a handful of studies on the correlates of mental disorders among older African Americans. Lastly, this investigation is important in a practical sense given the noted deleterious effects of negative interactions on mental health coupled with older African Americans' heavy reliance on social networks in meeting day-to-day needs.

\section{Methods}

Sample

The NSAL was collected by the Program for Research on Black Americans at the University of Michigan's Institute for Social Research. It is the most comprehensive and detailed study of mental disorders and the mental health of Americans of African descent ever completed (Jackson et al., 2004). The NSAL focuses on the physical, emotional, mental, structural, and economic conditions of African Americans, with a major emphasis on mental health and mental illness.

The field work for the study was completed by the Institute for Social Research's Survey Research Center, in cooperation with the Program for Research on Black Americans. Data were collected from 2001 to 2003. The NSAL sample consists of 64 primary sampling units. Fifty-six of these primary areas overlap substantially with existing Survey Research Center's National Sample primary areas. The remaining eight primary areas were chosen from the South in order for the sample to represent African Americans in the proportion in which they are distributed nationally.

A total of 6082 face-to-face interviews were conducted with persons aged 18 or older, including 3570 African Americans, 891 non-Hispanic whites, and 1621 blacks of Caribbean descent. The interviews were conducted in respondents' homes and they were compensated for their time. There were 786 African Americans age 55 and older with complete data. The overall response rate was $72.3 \%$. This response rate is excellent when considering that African Americans (especially lower income African Americans) are more likely to reside in major urban areas which are more difficult and much more expensive to collect interviews. The NSAL sample is discussed in detail elsewhere (Jackson et al., 2004).

\section{Demographic description of the sample}

The respondents in this older African American sample ranged from 55 to 93 years of age $(M=66.62$; $\mathrm{SD}=7.26)$. Approximately $60 \%$ of the respondents are women. Four out of $10(39.71 \%)$ are married, 3 out of $10(31.82 \%)$ are widowed, and 3 out of 10 respondents $(28.47 \%)$ are divorced, separated, or never married. More than half $(55.6 \%)$ of the sample resides in the South. With regards to socioeconomic status, the average imputed family income is $\$ 32881(\mathrm{SD}=\$ 33110)$ and the average years of education is $11.48(\mathrm{SD}=2.96)$. One third of the respondents $(33.86 \%)$ indicate that they are currently employed while only 1 in 20 (4.69\%) are currently unemployed. The remainder of the respondents $(61.44 \%)$ indicate that they are not in the labor force.

\section{Measures}

Three dependent variables are utilized in this analysis: (1) lifetime mood disorders, (2) lifetime anxiety disorders, and (3) number of lifetime mood and anxiety disorders. The DSM-IV World Mental Health Composite International Diagnostic Interview (WMH-CIDI), a fully structured diagnostic interview, was used to assess mood and anxiety disorders. The mental disorders sections used for NSAL are slightly modified versions of those developed for the World Mental Health Project initiated in 2000 (World Health Organization, 2004) and the instrument used in the National Comorbidity Survey-Replication (NCSR) (Kessler and Ustun, 2004). Anxiety disorders include: panic disorder, agoraphobia, social phobia, generalized anxiety disorder, obsessive-compulsive disorder, and posttraumatic stress disorder. Mood disorders include: major depressive disorder, dysthymia, and bipolar I and II disorders. Obsessive-compulsive disorder was assessed using the CIDI-short forms (Kessler et al., 1998). The number of disorders is a count of the number of mood and anxiety disorders.

Emotional support (an affective dimension of social support) is measured by an index of three items. Respondents were asked 'Other than your (spouse/ partner) how often do your family members: (1) make you feel loved and cared for, (2) listen to you talk about your private problems and concerns, and (3) express interest and concern in your well-being?' Response categories range from 'very often' to 'never' with higher values on this index indicating higher levels of emotional support. Cronbach's $\alpha$ for this 3 -item index is 0.72 . Negative interaction is also measured by an index of three items. Respondents were asked 'Other than your (spouse/partner) how often do your family members: (1) make too many demands on you?, (2) criticize you and the things you do?, and (3) try to take advantage of you?' The response categories for 
these questions were 'very often', 'fairly often', 'not too often', and 'never'. Higher values on this index indicate higher levels of negative interaction with family members (Cronbach's $\alpha=0.75$ ). For purposes of bivariate analysis only, low, medium, and high levels of emotional support and negative interaction were derived from tertiles of the indices.

\section{Analysis strategy}

Cross-tabulations are presented to illustrate demographic differences in prevalence of disorders. The percentages represent weighted proportions based on the distribution of African Americans in the population. The standard errors reflect the recalculation of variance using the study's complex design. The RaoScott $\chi^{2}$ represents a complex design-corrected measure of association. Logistic regression analysis was used to examine the effect of emotional support and negative interaction on the prevalence of mood and anxiety disorders. Odds ratio estimates and 95\% confidence intervals are presented along with the design-corrected $F$ statistic. Negative binomial regression was used to examine the effect of emotional support and negative interaction on the number of mood and anxiety disorders for which respondents met criteria. Rate ratio estimates and 95\% confidence intervals are presented. All analyses were conducted using Stata 9.2 which uses the Taylor expansion approximation technique for calculating the complex design-based estimates of variance.

\section{Results}

Almost one out of four respondents (22.93\%) had one mental disorder over the course of their lifetime, $13.23 \%$ of respondents had a lifetime anxiety disorder, and $6.33 \%$ had a lifetime mood disorder. One in 10 $(10.14 \%)$ respondents reported having two or more disorders in their lifetime and the number of mood and anxiety disorders ranged from 0 to 6 and had a mean of 0.3 .

Bivariate analyses (Table 1) indicate that among persons reporting a mood or anxiety disorder, a greater proportion were 55-64 years old. Those with mood or anxiety disorder were more likely to be female, have less than a high school education, were not working, and had less than $\$ 21000$ in household income. They were also more likely to be previously married compared to respondents with no psychiatric disorder. Roughly equal proportions of respondents with mood or anxiety disorder reside in the South, while most

Table 1 Characteristics of respondents by disorder $(N=786)$

\begin{tabular}{|c|c|c|c|}
\hline & No disorder $n=652 \%$ (SE) & Mood disorder $n=62 \%$ (SE) & Anxiety disorder $n=106 \%$ (SE) \\
\hline \multicolumn{4}{|l|}{ Age } \\
\hline $55-64$ & $43.1(1.9)$ & $66.1(6.0)$ & $58.5(4.8)$ \\
\hline $65-74$ & $37.0(1.8)$ & $27.4(5.7)$ & $32.1(4.5)$ \\
\hline $75+$ & $19.9(1.5)$ & $6.5(3.1)$ & $9.4(2.8)$ \\
\hline \multicolumn{4}{|l|}{ Gender } \\
\hline Male & $37.3(1.8)$ & $29.0(5.8)$ & $26.4(4.3)$ \\
\hline Female & $62.7(1.8)$ & $71.0(5.8)$ & $73.6(4.3)$ \\
\hline \multicolumn{4}{|l|}{ Education } \\
\hline$<12$ years & $42.7(1.9)$ & $45.9(6.4)$ & $49.5(4.9)$ \\
\hline 12 years & $29.9(1.8)$ & $39.3(6.3)$ & $29.5(4.5)$ \\
\hline$\geq 13$ years & $27.4(1.7)$ & $14.8(4.5)$ & $20.9(4.0)$ \\
\hline \multicolumn{4}{|l|}{ Employment status } \\
\hline Employed & $33.7(1.8)$ & $37.1(6.1)$ & $26.4(4.3)$ \\
\hline Not working & $62.2(1.8)$ & $54.8(6.3)$ & $65.1(4.6)$ \\
\hline Unemployed & $4.0(0.7)$ & $8.1(3.5)$ & $8.5(2.7)$ \\
\hline \multicolumn{4}{|l|}{ Income } \\
\hline$<\$ 21000$ & $56.3(1.9)$ & $67.7(5.9)$ & $67.9(4.5)$ \\
\hline$\geq \$ 21000$ & $43.7(1.9)$ & $32.3(5.9)$ & $32.1(4.5)$ \\
\hline \multicolumn{4}{|l|}{ Marital status } \\
\hline Married/partner & $31.5(1.8)$ & $24.2(5.4)$ & $21.7(4.0)$ \\
\hline Widowed & $36.7(1.8)$ & $29.0(5.8)$ & $36.8(4.7)$ \\
\hline Divorced & $18.5(1.5)$ & $29.0(5.8)$ & $24.5(4.2)$ \\
\hline Separated & $6.5(0.9)$ & $9.7(3.8)$ & $6.6(2.4)$ \\
\hline Never married & $6.8(1.0)$ & $8.1(3.5)$ & $10.4(3.0)$ \\
\hline \multicolumn{4}{|l|}{ Region } \\
\hline South & $64.6(1.8)$ & $53.2(6.3)$ & $50.0(4.9)$ \\
\hline Northeast, midwest, west & $35.4(1.8)$ & $46.8(6.3)$ & $50.0(4.9)$ \\
\hline
\end{tabular}


Table 2 Characteristics of respondents by number of disorders $(N=786)$

\begin{tabular}{|c|c|c|c|}
\hline & No disorder $n=652 \%$ (SE) & One disorder $n=78 \%$ (SE) & Two or more disorders $n=56 \%$ (SE) \\
\hline \multicolumn{4}{|l|}{ Age } \\
\hline $55-64$ & $43.1(1.9)$ & $59.3(7.0)$ & $59.5(7.3)$ \\
\hline $65-74$ & $37.0(1.8)$ & $32.5(7.0)$ & $32.1(7.8)$ \\
\hline $75+$ & $19.9(1.5)$ & $8.3(3.5)$ & $8.4(3.6)$ \\
\hline \multicolumn{4}{|l|}{ Gender } \\
\hline Male & $37.3(1.8)$ & $36.5(4.8)$ & $29.8(6.0)$ \\
\hline Female & $62.7(1.8)$ & $63.5(4.8)$ & $70.2(6.0)$ \\
\hline \multicolumn{4}{|l|}{ Education } \\
\hline$<12$ years & $42.7(1.9)$ & $38.2(6.1)$ & $50.6(5.8)$ \\
\hline 12 years & $29.9(1.8)$ & $33.3(6.4)$ & $33.3(8.2)$ \\
\hline$\geq 13$ years & $27.4(1.7)$ & $28.5(5.7)$ & $16.1(6.6)$ \\
\hline \multicolumn{4}{|l|}{ Employment status } \\
\hline Employed & $33.7(1.8)$ & $38.6(7.1)$ & $26.4(6.5)$ \\
\hline Not working & $62.2(1.8)$ & $52.5(6.9)$ & $67.3(6.2)$ \\
\hline Unemployed & $4.0(0.7)$ & $8.9(3.4)$ & $6.3(3.3)$ \\
\hline \multicolumn{4}{|l|}{ Income } \\
\hline$<\$ 21000$ & $56.3(1.9)$ & $54.5(6.1)$ & $68.0(8.2)$ \\
\hline$\geq \$ 21000$ & $43.7(1.9)$ & $45.5(6.1)$ & $32.0(8.2)$ \\
\hline \multicolumn{4}{|l|}{ Marital status } \\
\hline Married/partner & $31.5(1.8)$ & $25.2(5.6)$ & $33.0(5.4)$ \\
\hline Widowed & $36.7(1.8)$ & $31.2(5.5)$ & $31.2(7.1)$ \\
\hline Divorced & $18.5(1.5)$ & $20.6(5.2)$ & $21.1(4.9)$ \\
\hline Separated & $6.5(0.9)$ & $8.4(3.8)$ & $7.1(4.5)$ \\
\hline Never married & $6.8(1.0)$ & $14.6(7.1)$ & $7.7(3.8)$ \\
\hline \multicolumn{4}{|l|}{ Region } \\
\hline South & $64.6(1.8)$ & $52.2(8.1)$ & $38.7(5.5)$ \\
\hline Northeast, midwest, west & $35.4(1.8)$ & $47.8(8.1)$ & $61.3(5.5)$ \\
\hline
\end{tabular}

respondents without disorders live in the South. Bivariate analysis of the number of disorders (Table 2) also indicates that younger respondents (55-64), women, those with lower levels of income and education, and non-Southerners had more disorders.

Figure 1 represents the bivariate associations between emotional support and the presence of mood and anxiety disorder. There are no significant differences in the distribution of mood or anxiety disorder by reported level of emotional support from

A. Mood Disorder

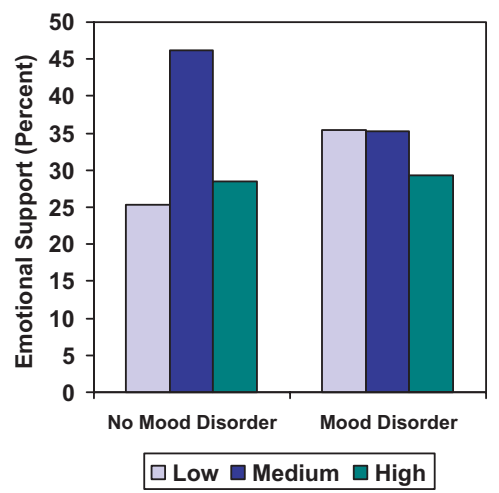

family members. The association between negative interaction and the presence of mood or anxiety disorder is depicted in Figure 2. Respondents without a psychiatric disorder report lower levels of negative interaction with family members compared to respondents reporting either a mood or anxiety disorder. Among the 'no disorder group', a greater proportion indicated low negative interaction with family, as compared to those reporting either medium or high negative interaction. Figure 3 presents the bivariate

\section{B. Anxiety Disorder}

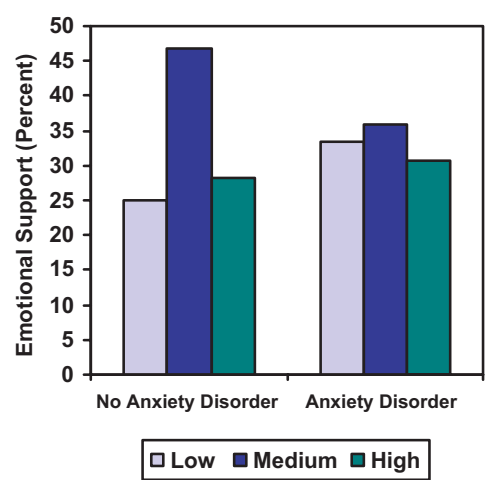

Figure 1 Level of emotional support by DSM-IV disorder. (A) Mood disorder, (B) anxiety disorder. $F$-test (1.99,65.58) for mood disorder $=1.353$, $p$-value $=0.266 ; F$-test ${ }_{(1.94,64.16)}$ for anxiety disorder $=1.722, p$-value $=0.188$. This figure is available in colour online at www.interscience.wiley.com/ journal/gps 
A. Mood Disorder

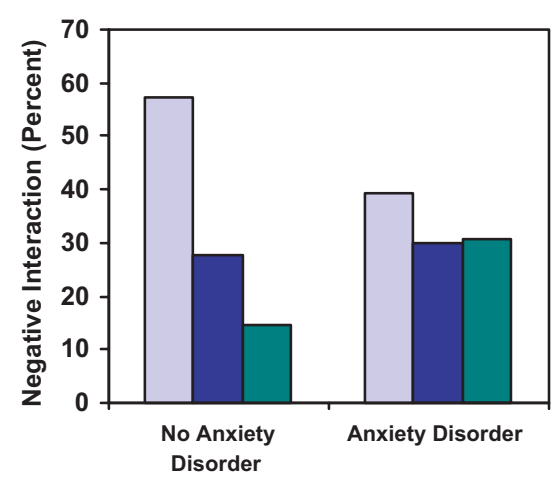

$\square$ Low $\square$ Medium $\square$ High

\section{B. Anxiety Disorder}

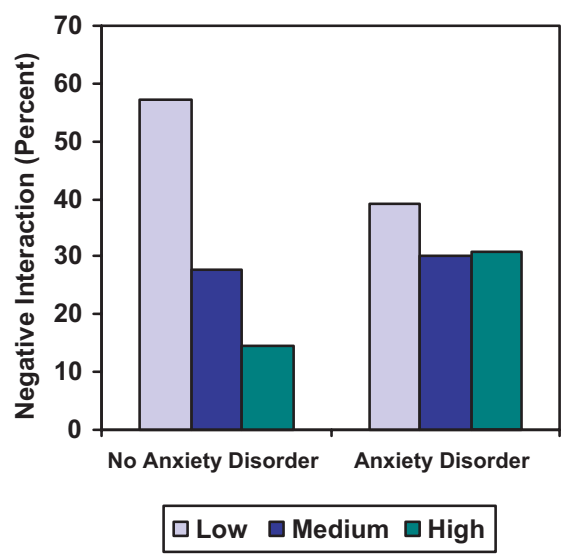

Figure 2 Level of negative interaction by DSM-IV disorder. (A) Mood disorder, (B) anxiety disorder. $F$-test $(1.92,63.25)$ for mood disorder $=4.065$, $p$-value $=0.023 ; F$-test $(1.83,60.43)$ for anxiety disorder $=9.419, p$-value $<0.001$. This figure is available in colour online at www.interscience.wiley.com/ journal/gps

A. Emotional Support

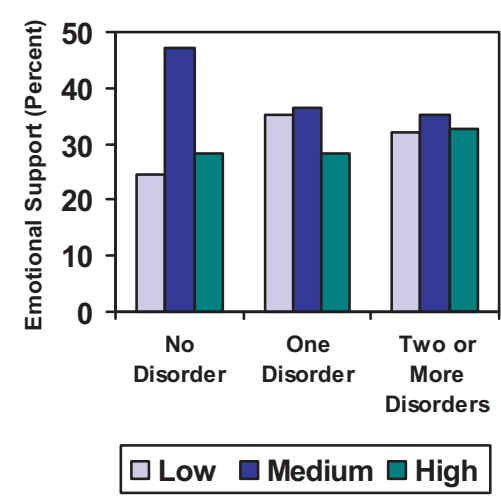

B. Negative Interaction

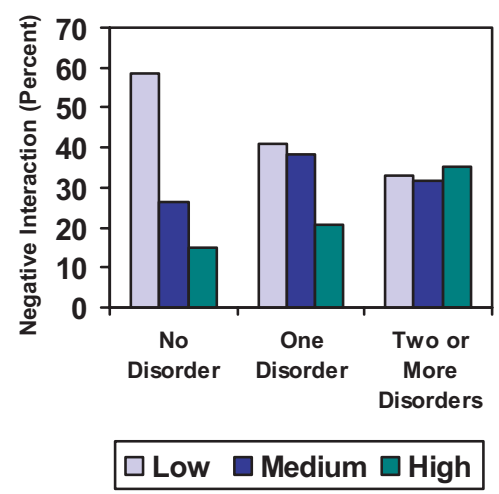

Figure 3 Level of emotional support and negative interaction by number of disorders. (A) Emotional support, (B) negative interaction. $F$-test $(3.72,122.78)$ for emotional support $=1.428, p$-value $=0.232 ; F$-test ${ }_{(3.05,100.49)}$ for negative interaction $=6.162, p$-value $<0.001$. This figure is available in colour online at www.interscience.wiley.com/journal/gps

associations between emotional support, negative interaction, and the number of disorders. Emotional support from family members was not associated with the number of disorders but respondents with more disorders reported more frequent negative interactions with family members.

The multivariate relationships between emotional support, negative interaction, and mood or anxiety disorders are shown in Table 3. Emotional support from family members was not associated with mood disorder, anxiety disorder, or the number of disorders. On the other hand, negative interaction with family members was positively associated with the presence of a mood disorder and the presence of an anxiety disorder after controlling for age, gender, employment status, income, education, marital status, and region. Negative interaction with family members was also positively associated with the number of disorders for which respondents met criteria after adjusting for covariates.

\section{Discussion}

The current study examined the association between emotional support and negative interaction with family members and psychiatric disorders among older African Americans. Similar to previous studies of negative interaction and mental disorders (Zlotnick et al., 2000; Bertera, 2005) and psychological distress (Lincoln et al., 2003a, 2005), our findings indicated 
Table 3 Multivariate regression of DSM-IV disorders and number of DSM-IV disorders

\begin{tabular}{lccc}
\hline & Mood disorder $^{\mathrm{a}}$ & Anxiety disorder $^{\mathrm{a}}$ & Number of mood and anxiety disorders $^{\mathrm{b}}$ \\
\hline Independent variable & OR $(95 \% \mathrm{Cl})$ & OR $(95 \% \mathrm{Cl})$ & $\mathrm{RR}(95 \% \mathrm{Cl})$ \\
Final model $^{\mathrm{c}}$ & & & \\
Emotional support & $0.99(0.84,1.15)$ & $0.95(0.83,1.08)$ & $1.01(0.93,1.10)$ \\
& $p=0.871$ & $p=0.398$ & 0.734 \\
Negative interaction & $1.12(1.02,1.25)$ & $1.18(1.05,1.32)$ & $1.14(1.05,1.23)$ \\
& $p=0.025$ & $p=0.006$ & 0.002 \\
$F_{13,21}$ & 4.16 & 0.15 & 6.03 \\
Prob $>F$ & 0.002 & 0.09 & $<0.001$ \\
\hline
\end{tabular}

Note: Significance test of the individual parameter estimates were based on a complex design-corrected $t$-test. $\mathrm{OR}=$ odds ratio; $\mathrm{RR}=$ rate ratio; $95 \% \mathrm{CI}=95 \%$ confidence interval.

${ }^{\mathrm{a}}$ Multivariate logistic odds ratio (95\% confidence interval) and $p$-values were reported.

${ }^{\mathrm{b}}$ Negative binomial regression rate ratio (95\% confidence interval) and $p$-values were reported.

${ }^{\mathrm{c}}$ Age, gender, employment status, income, education, marital status, and region were controlled for in the final models.

that negative interaction was associated with greater odds of having a mood disorder, an anxiety disorder, and the number of mood and anxiety disorders. Our results identify negative interaction with family members as a risk factor for poor mental health among older African Americans, and highlight the robust influence of negative interaction on both mood and anxiety disorders.

What is not evident from our findings are the causal relationships between negative interactions with family members and anxiety and mood disorders. That is to say, to what degree do negative interactions with family contribute to the development of anxiety or mood disorders, versus the degree to which they are the result of having a disorder. The presence of an anxiety or mood disorder can be the cause of significant distress in families that can easily lead to negative interactions with family members. For instance, an individual suffering from depression may experience symptomrelated social withdrawal that may give rise to criticisms from family members for not acting 'normal'. Similarly, symptoms of specific anxiety disorders (e.g., compulsive rituals in OCD) may elicit criticism from family members.

The evidence, however, is less clear and consistent regarding the role of negative interactions in the development of anxiety and mood disorders. Research in the area of 'childhood adversity' indicates that the quality of interactions with family in early life is consequential for mental health status. For example, research using both treatment and community samples found that adults who suffer from mental disorders were more likely to report having been exposed to serious hardships during childhood (Kessler et al., 1997). This includes a range of difficulties during childhood including parental emotional abuse, sexual abuse, parental substance abuse, parental depression, being in a life threatening accident or disaster, and the death of a parent (Kessler et al., 1997; Wilson et al., 2006). However, these childhood circumstances involve varying degrees of physical and emotional trauma and are qualitatively different from negative interactions with family. Recently, Waldinger et al. (2007) examined the impact of negative interactions during childhood on psychiatric disorders as an adult. Using data from a 30-year prospective study, they found that difficult relations with siblings prior to age 20 was associated with the occurrence of major depressive disorder and use of mood altering drugs by the age of 50. However, Waldinger et al. (2007) caution that because the associations involved are so complex, a causal relationship cannot be assumed even given this 30 -year prospective data.

Because our study is cross-sectional, we cannot determine causal relationships between negative interaction and anxiety and mood disorders. Even with a longitudinal study design, it can be difficult to distinguish between negative interaction with family members as an antecedent to, or as a result of psychiatric disorder. Over time and with a long history of association, negative interactions and anxiety and mood disorders may develop reciprocal patterns of association and influence. For persons with mood or anxiety disorders, criticisms and other negative interactions with family members can lead to an exacerbation of symptoms which, in turn, lead to more negative interactions and a further deterioration of the relationship.

Our findings also are consistent with research on expressed emotion and perceived criticism within 
clinical samples of patients with schizophrenia, as well as mood and anxiety disorders (Hooley, 2007). Expressed emotion is measured through an interview with a key family member (e.g., parent and spouse) and assesses the degree of criticism, hostility, or emotional over-involvement the relative expresses about the family member with the psychiatric disorder. This research consistently finds that the risk of relapse is higher for schizophrenic patients whose families are characterized by high levels of expressed emotion (Butzlaff and Hooley, 1998; Lopez et al., 2004). Although these findings are consistent with those of the present study, it is important to note that there are important sample and methodological differences between research on expressed emotion (i.e., treatment samples and interview with key family members) and negative interaction (i.e., community samples, interviews with respondents with and without mental disorders).

In the current investigation, emotional support from family members was not a significant correlate of having a mood disorder, an anxiety disorder, or the number of mood and anxiety disorders; indicating that negative interaction with family members is a more significant predictor of psychiatric disorders than emotional support. This is consistent with the larger body of literature that examines the simultaneous effects of positive and negative aspects of social relationships. For instance, research on psychological distress among African Americans found that negative interaction was associated with psychological distress, while emotional support was not (Lincoln et al., 2005, 2007). In analysis using the 1990-1992 NCS, Bertera (2005) found that negative interaction was consistently associated with the number of 12-month mood and anxiety disorders, while emotional support was not consistently associated with these variables (Bertera, 2005). Recent analysis by Kiecolt et al. (2008) also using the 1990-1992 NCS found that among African Americans, emotional support from family and spouse were inversely associated with the odds of having a 12-month mental disorder, but emotional support from friends did not have a significant association (Kiecolt et al., 2008). Unlike the present analysis, these studies examined 12-month, as opposed to lifetime disorders and the NCS sample's upper age range was 54 years.

The results of this study have important clinical implications. The reduction of negative family interactions is a potentially valuable intervention target that is not commonly included in empirically supported psychosocial treatment manuals for anxiety (Craske and Barlow, 2006; Craske et al., 2006; Foa et al., 2007) and depressive disorders (Freeman and Gilson, 2009). Interventions that target high levels of negative expressed emotion among families with a schizophrenic member have been shown to be effective in reducing both positive and negative symptoms of this disorder (McFarlane et al., 2003). Preliminary evidence also suggests that similar interventions can be modified to address certain anxiety (Van Noppen and Steketee, 2003; Weine et al., 2008) and depressive (Sanford et al., 2006) disorders with beneficial effects. Future research examining the value of interventions aimed at reducing negative interaction among African Americans with depressive and anxiety disorders and their family members is clearly needed.

\section{Limitations}

This study has several limitations. First, because several segments of the population such as homeless and institutionalized individuals were not represented, our findings are not generalizable to these subgroups. Second, disorder-specific symptoms and behaviors may be underreported (potentially resulting in lower prevalence rates) due to item non-response to sensitive questions which is a common issue in survey interviewing. Third, the number of cases for several of the lifetime disorders is low and, consequently, we are unable to conduct disorder-specific analyses. Fourth, it would have been preferable to examine 12month as opposed to lifetime disorders to lessen the temporal differences between the dependent and social relationship variables. However, the number of cases of 12-month disorders was too few to conduct reliable analysis. Finally, as noted earlier, causal inferences are problematic with cross-sectional data and longitudinal data are preferred. Nonetheless, the significant advantages of the sample provided the first opportunity to examine the impact of emotional support and negative interaction on psychiatric disorders among older African Americans.

\section{Conclusions}

The present findings are important for understanding the relationship between family interactions and mental disorders. Prior literature indicates that emotional support is beneficial for health and wellbeing. However, relatively few studies have examined the adverse effects of negative interactions with family on psychiatric disorders. While questions as to the precise etiology of psychiatric disorders can only be 


\section{Key points}

- Negative interaction is a risk factor for mood and anxiety disorders among older African Americans. The reduction of negative family interactions is a potentially valuable intervention target that is not commonly included in empirically supported psychosocial treatment manuals for anxiety depressive disorders.

addressed with prospective data, information on negative family interactions may be important in understanding contemporaneous aspects of family environment. Study findings alert clinicians to the potential negative impacts of family involvement and their implications for psychiatric disorders. Importantly, this study explored the relationship between negative interaction with family members on mood and anxiety disorders in a population for which there was no prior information.

\section{Conflict of interest}

None known.

\section{Acknowledgements}

Data collection on which this study is based was supported by the National Institute of Mental Health (NIMH; U01-MH57716), the Office of Behavioral and Social Science Research at the National Institutes of Health (NIH), and the University of Michigan. Preparation of this manuscript was supported by grants from the NIMH to KDL (K01-MH069923), National Institute on Aging to LMC and RJT (R01 AG18782), and RJT and JSJ (P30AG1528).

\section{References}

Bertera EM. 2005. Mental health in U.S. adults: the role of positive social support and social negativity in personal relationships. J Soc Pers Relat 22: 33-48.

Bolger N, DeLongis A, Kessler RC, Schilling EA. 1989. Effects of daily stress on negative mood. J Pers Soc Psychol 57: 808-818.

Butzlaff RL, Hooley JM. 1998. Expressed emotion and psychiatric relapse: a meta-analysis. Arch Gen Psychiatry 55: 547-552.

Chatters LM, Taylor RJ, Lincoln KD, Schroepfer T. 2002. Patterns of informal support from family and church members among African Americans. J Black Stud 33: 66-85.
Cohen S, Doyle WJ, Skoner DP, Rabin BS, Gwaltney JM. 1997. Social ties and susceptibility to the common cold. J Am Med Assoc 277: 1940-1944.

Craske MG, Antony MM, Barlow DH. 2006. Mastering Your Fears and Phobias. Oxford University Press: New York.

Craske MG, Barlow DH. 2006. Mastery of Your Anxiety and Panic. Oxford University Press: New York.

Dilworth-Anderson P, Williams SW, Cooper T. 1999. Family caregiving to elderly African Americans: caregiver types and structures. J Gerontol B Psychol Sci Soc Sci 54B: 349-366.

Foa E, Rothbaum BO, Hembree E. 2007. Prolonged Exposure Therapy for PTSD: Emotional Processing of Traumatic Experiences. Oxford University Press: New York.

Ford BC, Bullard KM, Taylor RJ, et al. 2007. Lifetime and twelve-month prevalence of DSM-IV disorders among older African Americans: findings from the National Survey of American Life (NSAL). Am J Geriatr Psychiatry 15: 652-659.

Freeman A, Gilson M. 2009. Overcoming Depression: A Cognitive-therapy Approach. Oxford University Press: New York.

Hooley JM. 2007. Expressed emotion and relapse of psychopathology. Annu Rev Clin Psychol 3: 329-352.

Jackson JS, Torres M, Caldwell CH, et al. 2004. The National Survey of American Life: a study of racial, ethnic and cultural influences on mental disorders and mental health. Int J Methods Psychiatr Res 13: 196-207.

Kessler RC, Andrews G, Mroczek D, Ustun TB, Wittchen HU. 1998. The world health organization composite international diagnostic interview. Int J Methods Psychiatr Res 7: 171-185.

Kessler RC, Davis CG, Kendler KS. 1997. Childhood adversity and adult psychiatric disorder in the U.S. National Comorbidity Survey. Psychol Med 27: 1101-1119.

Kessler RC, Ustun TB. 2004. The World Mental Health (WMH) survey initiative version of the World Health Organization (WHO) composite International Diagnostic Interview (CIDI). Int J Methods Psychiatr Res 13: 93-121.

Kiecolt KJ, Hughes M, Keith VM. 2008. Race, social relationships, and mental health. Pers Relat 15: 229-254.

King AC, Atienza A, Castro C, Collins R. 2002. Physiological and affective responses to family caregiving in the natural setting in wives versus daughters. Int J Behav Med 9: 176-194.

Krause N. 2005. Negative interaction and heart disease in late life: exploring variations by socioeconomic status. J Aging Health 17: 28-55.

Lincoln KD. 2000. Social support, negative social interactions and psychological well-being. Soc Serv Rev 74: 231-252.

Lincoln KD. 2007. Financial strain, negative interactions and mastery: pathways to mental health among older African Americans. J Black Psychol 33: 439-462.

Lincoln KD, Chatters LM, Taylor RJ. 2003a. Psychological distress among black and white Americans: differential effects of social support, negative interaction and personal control. J Health Soc Behav 44: 390407.

Lincoln KD, Chatters LM, Taylor RJ. 2005. Social support, traumatic events and psychological distress among African Americans. J Marriage Fam 67: 754-767.

Lincoln KD, Chatters LM, Taylor RJ, Jackson JS. 2007. Profiles of depressive symptoms among African Americans and Caribbean Blacks. Soc Sci Med 65: $200-213$

Lincoln KD, Taylor RJ, Chatters LM. 2003b. Correlates of emotional support and negative interaction among Black Americans. J Gerontol B Psychol Sci Soc Sci 58B: S225-S233.

Lopez SR, Nelson HK, Polo AJ, et al. 2004. Ethnicity, expressed emotion, attributions, and course of schizophrenia: family warmth matters. J Abnorm Psychol 113: 428-439.

McFarlane WR, Dixon L, Lukens E, Lucksted A. 2003. Family psychoeducation and schizophrenia: a review of the literature. J Marital Fam Ther 29: 223-245.

Mehta KM, Simonsick EM, Penninx B, et al. 2004. Prevalence and correlates of anxiety symptoms in well-functioning older adults: findings from the healthy aging and body composition study. J Am Geriatr Soc 12: 265-271.

Neighbors HW. 1997. Husbands, wives, family, and friends: sources of stress, sources of support. In Family Life in Black America, Taylor RJ, Jackson JS, Chatters LM (eds). Sage: Newbury Park, CA; 227-292. 
Newsom JT, Nishishiba M, Morgan D, Rook KS. 2003. The relative importance of three domains of positive and negative social exchanges: a longitudinal model with comparable measures. Psychol Aging 18: 746754 .

Newsom JT, Schulz R. 1998. Caregiving from the recipient's perspective: negative reactions to being helped. Health Psychol 17: 172-181.

Okereke OI, Faison WE. 2008. Ethnicity and geriatric psychiatry. Am J Geriatr Psychiatry 16: 945-947.

Okun M, Keith VM. 1998. Effects of positive and negative social exchanges with various sources on depressive symptoms. J Gerontol B Psychol Sci Soc Sci 53B: P4-P20.

Rook KS. 1984. The negative side of social interaction: impact on psychological well-being. J Pers Soc Psychol 46: 1097-1108.

Rook KS, Ituarte HG. 1999. Social control, social support and companionship in older adults' family relationships and friendships. Pers Relat 6: 199-211.

Sanford M, Boyle M, McCleary L, et al. 2006. Pilot study of adjunctive family psychoeducation in adolescent major depression: feasibility and treatment effect. J Am Acad Child Adolesc Psychiatry 45: 386-395.

Seeman T, Chen X. 2002. Risk and protective factors for physical functioning in older adults with and without chronic conditions. J Gerontol B Psychol Sci Soc Sci 57: S135-S144.

Tanne D, Goldbourt U, Medalie JH. 2004. Perceived family difficulties and prediction of 23-year stroke mortality among middle-aged men. Cerebrovasc Dis 18: 277-282.

Taylor RJ, Chatters LM, Celious AK. 2003. Extended family households among Black Americans. Afr Am Res Perspect 9: 133-151.
Taylor RJ, Chatters LM, Tucker MB, Lewis E. 1990. Developments in research on Black families: a decade review. J Marriage Fam 52: 993-1014.

Travis LA, Lyness JM, Shields CG, King DA, Cox C. 2004. Social support, depression, and functional disability in older adult primary-care patients. Am J Geriatr Psychiatry 12: 265-271.

Van Noppen B, Steketee G. 2003. Family responses and multifamily behavioral treatment for obsessive-compulsive disorder. Brief Treat Crisis Interv 3: 231-247.

Waldinger RJ, Vaillant GE, Orav EJ. 2007. Childhood sibling relationships as a predictor of major depression in adulthood: a 30-year prospective study. Am J Psychiatry 164: 949-954.

Weine S, Kulauzvoic Y, Klebic A, et al. 2008. Evaluating a multiple-family group access intervention for refugees with PTSD. J Marital Fam Ther 34: 149-164.

Wilson RS, Krueger KR, Arnold SE, et al. 2006. Childhood adversity and psychological adjustment in old age. Am J Geriatr Psychiatry 14: 307315 .

Woodward AT, Taylor RJ, Bullard KM, et al. 2008. The use of professional services and informal support among Black Americans with a mental disorder. Psychiatr Serv 59: 1292-1298.

World Health Organization. 2004. The prevalence, severity, and unmet need for treatment of mental disorders in the World Health Organization world mental health surveys. J Am Med Assoc 291: 2581-2590.

Zlotnick C, Kohn R, Keitner G, Grotta SA. 2000. The relationship between quality of interpersonal relationships and major depressive disorder: findings from the National Comorbidity Survey. J Affect Disord 59: 205-215. 